\title{
Lithiophilic Zn Sites in Porous CuZn Alloy Induced Uniform Li Nucleation and Dendrite-Free Li Metal Deposition
}

Shang-Sen Chi, ${ }^{\dagger, \S, \#}$ Qingrong Wang, ${ }^{\dagger, \#}$ Bing Han,${ }^{\dagger}$ Chao Luo, ${ }^{\dagger}$ Yidong Jiang, ${ }^{\dagger}$ Jun Wang, ${ }^{\dagger}$ Chaoyang Wang,

†Department of Materials Science and Engineering, Academy for Advanced Interdisciplinary Studies, Shenzhen Key Laboratory of Solid State Batteries, Guangdong Provincial Key Laboratory of Energy Materials for Electric Power, Southern University of Science and Technology (SUSTech), Shenzhen 518055, China.

$\S$ Hefei National Laboratory for Physical Sciences at the Microscale, Department of Materials Science and Engineering, CAS Key Laboratory of Materials for Energy Conversion, University of Science and Technology of China, Hefei, Anhui, 230026, China.

"Dalian National Laboratory for Clean Energy (DNL), Chinese Academy of Sciences (CAS), Dalian, Liaoning, China.

${ }^{\&}$ State Key Laboratory of Fire Science, University of Science and Technology of China, Hefei, Anhui, 230026, China. 
Research Institute of Materials Science, South China University of Technology, Guangzhou 510640, China.

*Corresponding Authors:

E-mail Addresses: yanyumse@ustc.edu.cn (Yan Yu); yhdeng08@163.com (Yonghong Deng)

\section{Contents List}

I. Experimental

II. Supplementary Tables and Figures 


\section{Experimental}

1.1 Materials preparation. The 3D porous $\mathrm{CuZn}$ was synthesized by a conventional chemical dealloying method. ${ }^{1,2}$ Firstly, the CuZn brass tape $(50 \mu \mathrm{m})$ was washed by consecutive ultrasonication using acetone, ethyl alcohol and deionized water each for $10 \mathrm{~min}$. Subsequently, it was put in the mixed solution comprising of $1 \mathrm{~mol} \mathrm{~L}^{-1}$ hydrochloric acid $(\mathrm{HCl})$ and $5 \mathrm{~mol}$ $\mathrm{L}^{-1}$ ammonium chloride $\left(\mathrm{NH}_{4} \mathrm{Cl}\right)$ in water bath at $80{ }^{\circ} \mathrm{C}$ for $14 \mathrm{~h}$. After dealloying, the samples were cleaned with distilled water and dehydrated alcohol for several times, and these agents were deaerated by purging $\mathrm{N}_{2}$ for 20 min. After drying in a vacuum chamber at $60^{\circ} \mathrm{C}$ for $6 \mathrm{~h}$, the as-prepared 3D porous CuZn was put on the top of the molten Li. Molten Li could steadily climb up and wet the whole 3D porous CuZn disk, forming the final Li composite electrode (Supporting Video 1). It is noticed that the melted liquid Li can easily infiltrate into the internal space of $3 \mathrm{D}$ porous $\mathrm{CuZn}$ alloy host, which is mainly owing to the capillary action. This phenomenon also confirms that the $3 \mathrm{D}$ porous $\mathrm{CuZn}$ host embodies stability against the melted Li. Finally, Li composite electrode was punched into circular disks with diameter of $14 \mathrm{~mm}$ as the working Li metal anode. Noteworthy, the freshly Li foil was put on a nickel plate to heat $\sim 500{ }^{\circ} \mathrm{C}$, and the melting process lasted about $2 \mathrm{~min}$. The molten liquefied Li draws into the whole 3D porous $\mathrm{CuZn}$ disk for about $8 \mathrm{~min}$.

1.2 Sample characterization. Field-emission SEM images and energy-dispersive X-ray spectroscopy (EDS) mappings were obtained on commercial SEM system (FE-SEM, Tescan mira3, Oxford, Czech Republic). Noticeably, before observing the morphology of the cycled electrodes, the batteries were firstly disassembled in the glovebox and then gently rinsed with dimethyl carbonate (DMC) to remove residual Li salts and electrolyte. 


\subsection{Operando investigation of Li stripping/plating behavior using the optical microscope.}

The Li deposition behavior was observed based on an in-situ cuvette cell. The cuvette cell comprised of two parallel electrodes was assembled in the sample stage of an optical microscope outfitted with extra-long working distance objectives for observing sectional morphological changes of the work electrodes in real time. The work electrode used in this experiment was either $\mathrm{Li} / \mathrm{CuZn}$ composite or bare Li electrode, and the counter electrode was bare Li foil. The cuvette was filled with $3 \mathrm{ml} 1.0 \mathrm{M}$ lithium hexafluorophosphate $\left(\mathrm{LiPF}_{6}\right)$ in a mixture of ethylene carbonate, ethyl methyl carbonate and dimethyl carbonate (EC: EMC: $\mathrm{DMC}=1: 1: 1$ vol.\%, CAPCHEM). The cell was connected with a Neware Battery Testing System for constant current density lithium deposition. The optical images were viewed with the optical microscope (200 times of magnification).

1.4 Computational details. Materials studio-CASTEP: Calculations were performed in the framework of density functional theory (DFT) on periodic super-cells using the generalized gradient approximation (GGA) of Perdew-Burke-Ernzerhof (PBE) functional. The k-point grid will be generated according to the specified k-point separation. The k-point separation is 0.04 $\AA^{-1}$. The plane-wave energy cutoff was set to $400 \mathrm{eV}$. In all calculations, we used (2*2) fivelayer fcc (111) slabs with theoretical equilibrium lattice constant to model the $\mathrm{Cu}(111)$ and $\mathrm{CuZn}$ (111) surfaces. Vacuum layers with thickness of $15 \AA$ were added above the top layer of slabs in all cases. The atoms in the bottom two layers are fixed at the theoretical bulk positions, whereas the top three layers on $(2 * 2)$ five-layer slabs are allowed to relax and all the other structural parameters have been optimized so as to minimize the total energy of the system. If in the plating process: $\mathrm{slab}+\mathrm{Li}=$ total. The adsorption energies are calculated with the energies 
of the bare $\mathrm{Cu}(111), \mathrm{Cu}_{0.64} \mathrm{Zn}_{0.36}(111)$ or $\mathrm{Zn}(101) \mathrm{slab}\left(\mathrm{E}_{\text {slab }}\right)$ and the isolated Li atom $\left(\mathrm{E}_{\mathrm{Li}}\right)$ as the references according to: $\mathrm{E}_{\mathrm{ads}}=\mathrm{E}_{\text {total }}-\mathrm{E}_{\mathrm{slab}}-\mathrm{E}_{\mathrm{Li}}$.

1.5 Electrochemical measurements. To probe the Coulombic efficiency of the 3D porous $\mathrm{CuZn}$ or bare $\mathrm{Cu}$ electrodes, the electrodes were assembled into standard 2025-type coin cells with bare Li foil as the counter electrodes. To fabricate NCM811 electrodes for the full-cell battery testing, the active material (NCM811 powder) was mixed with carbon black and polyvinylidene fluoride (PVDF) at a weight ratio of 8:1:1 with N-Methyl-2-pyrrolidone as the solvent. The areal mass loading of the NCM811 electrode was about $3.0 \mathrm{mg} \mathrm{cm}{ }^{-2}$. Celgard 2400 was utilized as the separator. The electrolyte employed was $1.0 \mathrm{M} \mathrm{LiPF}_{6}$ in a mixture of $\mathrm{EC}: \mathrm{EMC}: \mathrm{DMC}=1: 1: 1$ vol.\% (CAPCHEM). The dosage of the electrolyte in each cell is 80 $\mu \mathrm{L}$. Galvanostatic cycling was conducted on the Neware Battery Testing System. Electrochemical impedance spectrum (EIS) measurements were carried out on a Solartron analytical electrochemical workstation (mode 1260A, England) at $5 \mathrm{mV}$ over the frequency ranging from $100 \mathrm{kHz}$ to $0.01 \mathrm{~Hz}$. 


\section{Supplementary Tables and Figures}

Table S1. The Li content in different thickness of $\mathrm{Li} / \mathrm{CuZn}$ composite.

\begin{tabular}{|c|c|c|c|c|}
\hline Thickness & $\begin{array}{l}\text { Average weight of } \\
\text { the 3D porous } \mathrm{Cu} \\
\qquad / \mathrm{mg}\end{array}$ & $\begin{array}{l}\text { Average weight of } \\
\text { Li/Cu composite } \\
\text { I mg }\end{array}$ & $\begin{array}{l}\text { Areal loading of Li } \\
\text { in Li/Cu composite } \\
\qquad / \mathrm{mg} \mathrm{cm}^{-2}\end{array}$ & $\begin{array}{c}\text { Areal } \\
\text { capacity } \\
\text { I } \mathrm{mAh} \mathrm{cm}^{-2}\end{array}$ \\
\hline $20 \mu \mathrm{m}$ & 20.02 & 20.38 & 0.24 & 0.91 \\
\hline $50 \mu \mathrm{m}$ & 50.06 & 50.96 & 0.59 & 2.27 \\
\hline $100 \mu \mathrm{m}$ & 100.11 & 101.91 & 1.17 & 4.52 \\
\hline
\end{tabular}

Note: The $\mathrm{Li} / \mathrm{CuZn}$ composites with different thickness values were cut into small disks before the subsequent measurements. The weight of the 3D porous $\mathrm{CuZn}$ and $\mathrm{Li} / \mathrm{CuZn}$ composite were measured based on a disk of $1.538 \mathrm{~cm}^{2}$ (diameter of $1.4 \mathrm{~cm}$ ) for 20 samples. With the thickness of $100 \mu \mathrm{m} \mathrm{Li} / \mathrm{CuZn}$ composite as a sample, the areal loading of $\mathrm{Li}$ in $\mathrm{Li} / \mathrm{CuZn}$ composite is $(101.91-100.11) \mathrm{mg} \div 1.538 \mathrm{~cm}^{2} \approx 1.17 \mathrm{mg} \mathrm{cm}^{-2}$, and the corresponding areal capacity is $1.17 \mathrm{mg} \mathrm{cm}^{-2} \times 3860 \mathrm{mAh} \mathrm{g}^{-1} \approx 4.52 \mathrm{mAh} \mathrm{cm}^{-2}$. Weight percentage of Li in the $\mathrm{Li} / \mathrm{CuZn}$ composite is $1.766 \%$. 
Table S2. The average Coulombic efficiency and cycling life of different current collector in

Figure 2a and Figure S7.

\begin{tabular}{|c|c|c|c|c|}
\hline & Cu foil & CuZn-10h & CuZn-14h & CuZn-18h \\
\hline $0.5 \mathrm{~mA} \mathrm{~cm}^{-2}$ & $97.1 \%$, & $98.2 \%$, & $98.6 \%$, & $98.3 \%$, \\
\hline $0.5 \mathrm{mAh} \mathrm{cm}^{-2}$ & 412 cycles & 621 cycles & 850 cycles & 653 cycles \\
\hline $1 \mathrm{~mA} \mathrm{~cm}-2$ & $96.1 \%$, & $97.1 \%$, & $97.8 \%$, & $97.3 \%$, \\
\hline $1 \mathrm{mAh} \mathrm{cm}^{-2}$ & 172 cycles & 196 cycles & 285 cycles & 273 cycles \\
\hline $2 \mathrm{~mA} \mathrm{~cm}{ }^{-2}$ & $95.3 \%$, & $96.3 \%$, & $96.9 \%$, & $96.5 \%$, \\
\hline $1 \mathrm{mAh} \mathrm{cm}^{-2}$ & 125 cycles & 156 cycles & 236 cycles & 212 cycles \\
\hline
\end{tabular}

The Coulombic efficiency and cycling life of different 3D porous CuZn alloy in Figure 2a and Figure S7 are summarized in Table S2. As shown in Table S2, the Coulombic efficiency and the cycling life of the $\mathrm{CuZn}$ alloy with the dealloying time of $14 \mathrm{~h}$ in the $\mathrm{Li} / \mathrm{CuZn}$ cell is higher than that of the $\mathrm{CuZn}$ alloy with the dealloying time of $10 \mathrm{~h}$ or $18 \mathrm{~h}$. For this situation, it may be ascribed to two reasons. On the one hand, there are more $\mathrm{Zn}$ sites in the $3 \mathrm{D} \mathrm{CuZn}-14 \mathrm{~h}$ alloy than in the 3D CuZn-18h alloy, which can induce uniform Li nucleation and deposition. On the other hand, more pores in the 3D CuZn-14h alloy compared to the 3D CuZn-10h alloy can reduce the current density, which can lead to a dendrite-free Li metal deposition. 
Table S3 Simulation results of the EIS spectra of the bare Li foil and 3D Li/CuZn composite assembled symmetric cells before and after cycling in Figure S9.

\begin{tabular}{cccccc}
\hline \multicolumn{1}{c}{ Samples } & $\mathrm{R}_{\mathrm{S}}(\Omega)$ & $\mathrm{R}_{1}(\Omega)$ & $\mathrm{R}_{2}(\Omega)$ & $\mathrm{CPE}_{1}(\mathrm{~F})$ & $\mathrm{CPE}_{2}(\mathrm{~F})$ \\
\hline Bare Li-before cycling & 11.81 & 94.72 & 3.81 & 0.589 & 0.713 \\
Bare Li-after cycling & 9.21 & 58.28 & 1.79 & 0.527 & 0.689 \\
Li/CuZn-before cycling & 11.11 & 57.97 & 2.98 & 0.578 & 0.821 \\
Li/CuZn-after cycling & 8.69 & 53.67 & 2.24 & 0.542 & 0.981 \\
\hline
\end{tabular}

Note: Rs: The total resistance for the electrolyte, separator, and electrical contact resistances;

$\mathrm{R}_{1}$ : The SEI layer resistance; $\mathrm{R}_{2}$ : The resistance for the charge transfer on the electrolyte/electrode interface. Further analysis of the ohmic resistance values in Table S3 shows that the SEI layer impedance $\left(\mathrm{R}_{1}\right)$ of the $3 \mathrm{D} \mathrm{Li} / \mathrm{CuZn}$ composite assembled symmetric cells before and after cycling are lower than the bare Li foil symmetric cells, which means that the $3 \mathrm{D} \mathrm{Li} / \mathrm{CuZn}$ composite has better cycling performance than the bare $\mathrm{Li}$. 
(a) Non-uniform Li stripping/plating

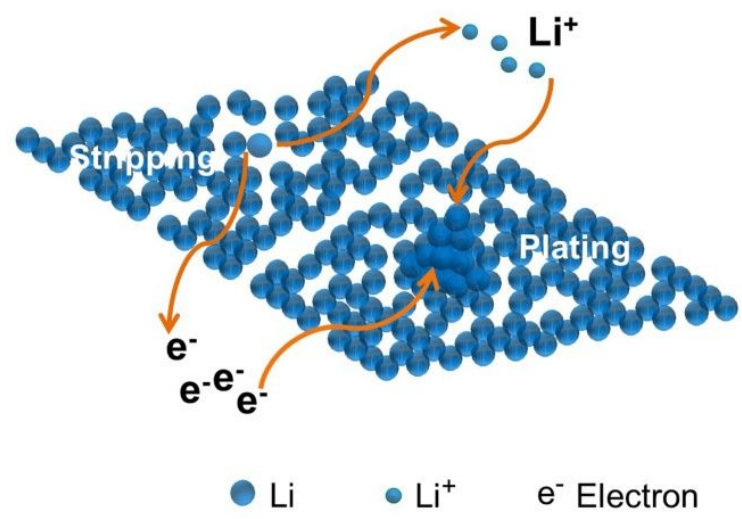

Bare Li metal anode (b) Uniform Li stripping/plating

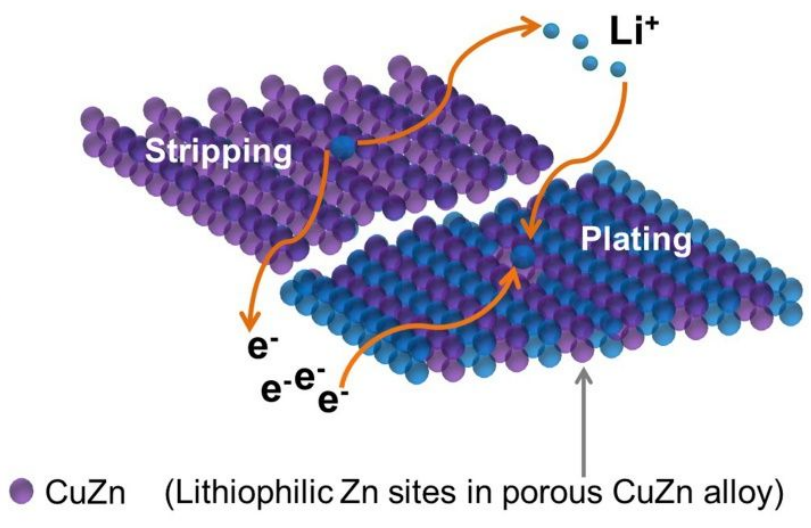

Li/CuZn composite anode

Figure S1. Schematically illustrating the structure evolution of the Li striping/plating process for (a) bare Li metal anode and (b) $\mathrm{Li} / \mathrm{CuZn}$ composite electrolyte in working Li metal batteries. 

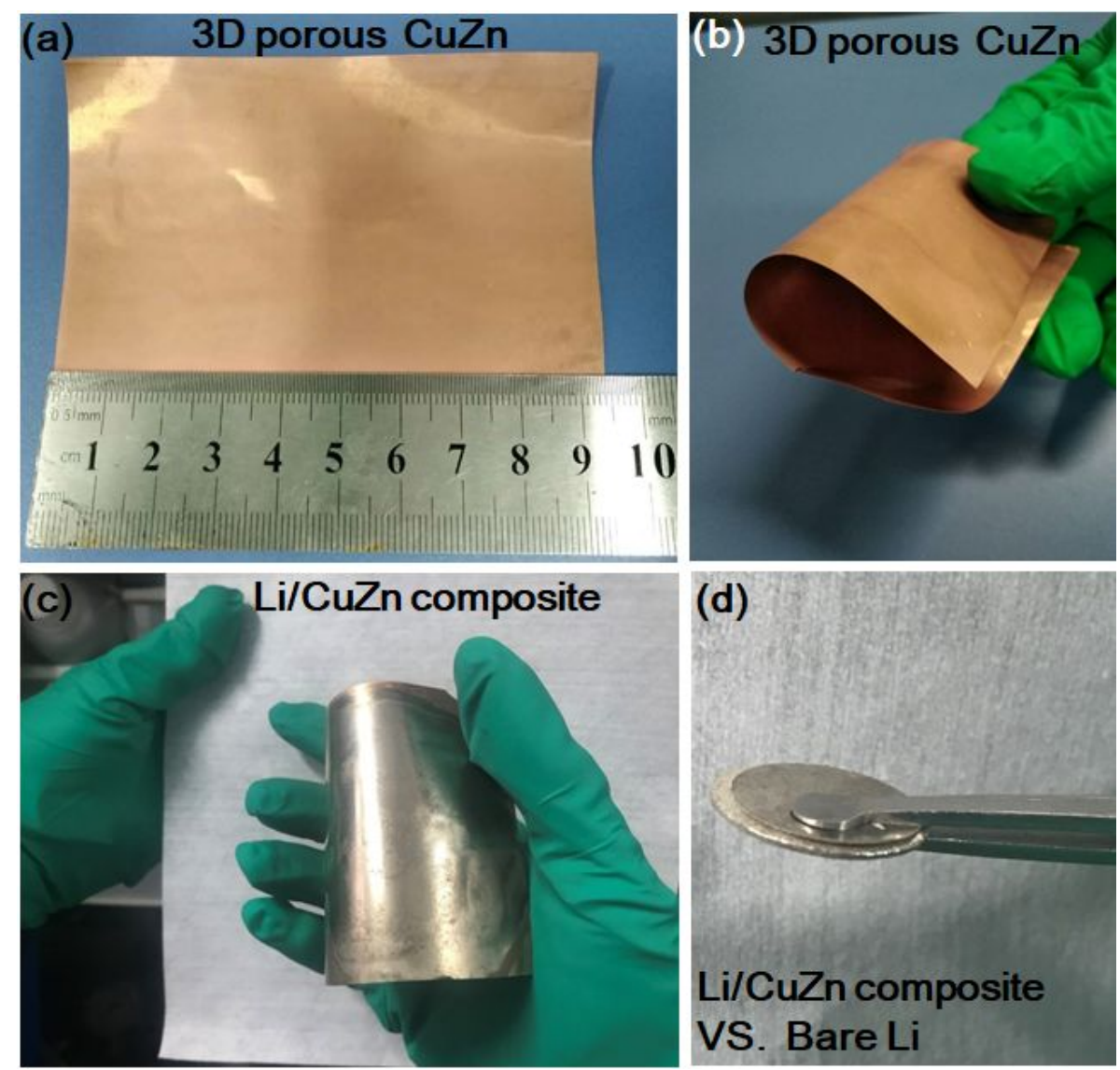

Figure S2. (a, b) Digital camera image of the 3D porous $\mathrm{CuZn}$, which exhibits a good flexibility when it bended. (c) Digital camera image of the $\mathrm{Li} / \mathrm{CuZn}-14 \mathrm{~h}$ composite, which also exhibits a good flexibility when it bended. (d) Digital camera image of the Li/CuZn-14h composite compared with bare $\operatorname{Li}(400 \mu \mathrm{m})$, which shows a thin thickness. 


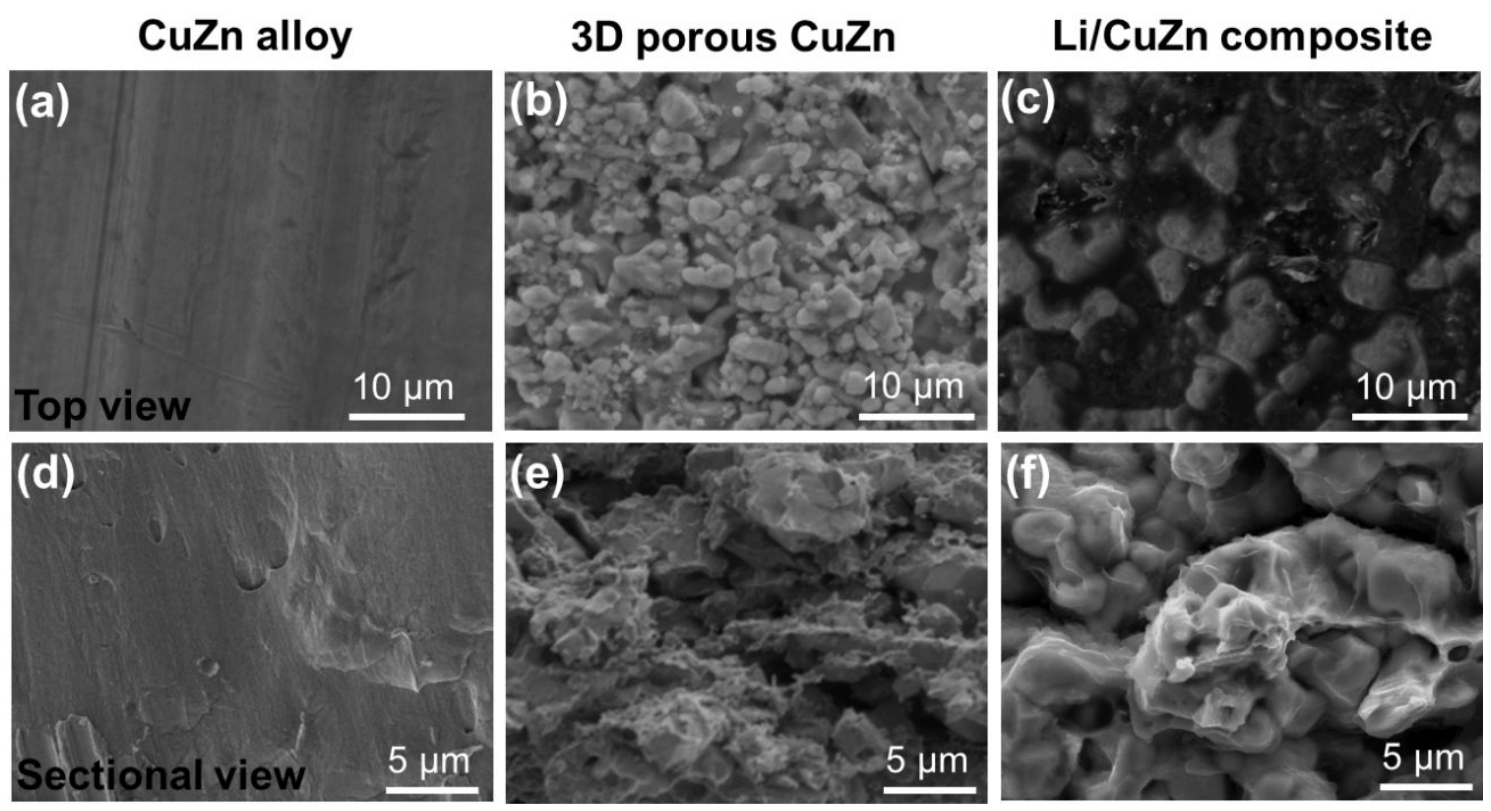

Figure S3. Magnified surface and cross sectional SEM images of $\mathrm{CuZn}$ alloy (a, d), 3D porous CuZn-14h (b, e), and Li/CuZn-14h composite (c, f). 

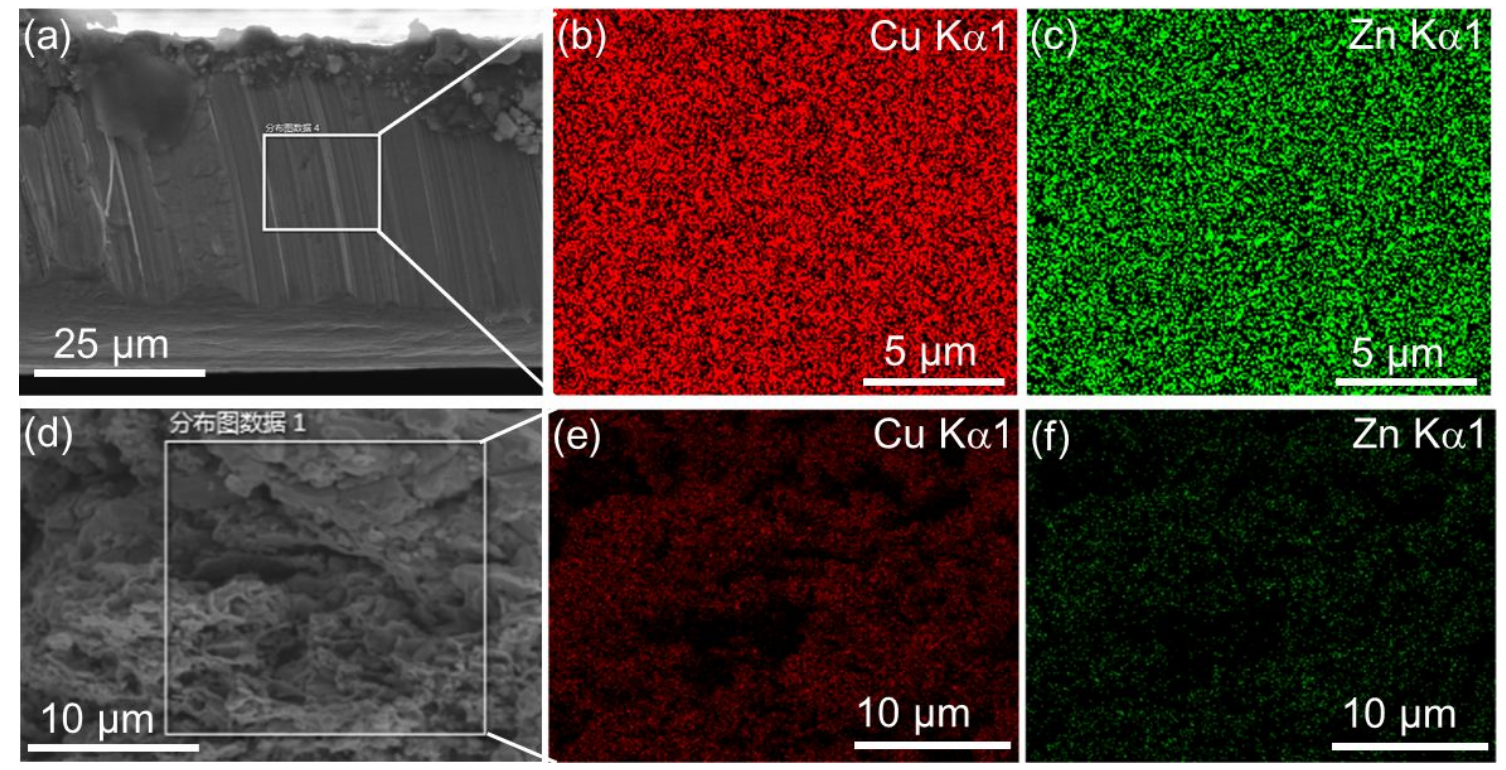

Figure S4. (a) Cross sectional SEM image of CuZn alloy and 3D porous $\mathrm{CuZn}-14 \mathrm{~h}$, and corresponding elemental mapping images of (b) $\mathrm{Cu}$ and (c) Zn. (d) Cross sectional SEM image of 3D porous $\mathrm{CuZn}-14 \mathrm{~h}$, and corresponding elemental mapping images of (e) $\mathrm{Cu}$ and (f) $\mathrm{Zn}$. 


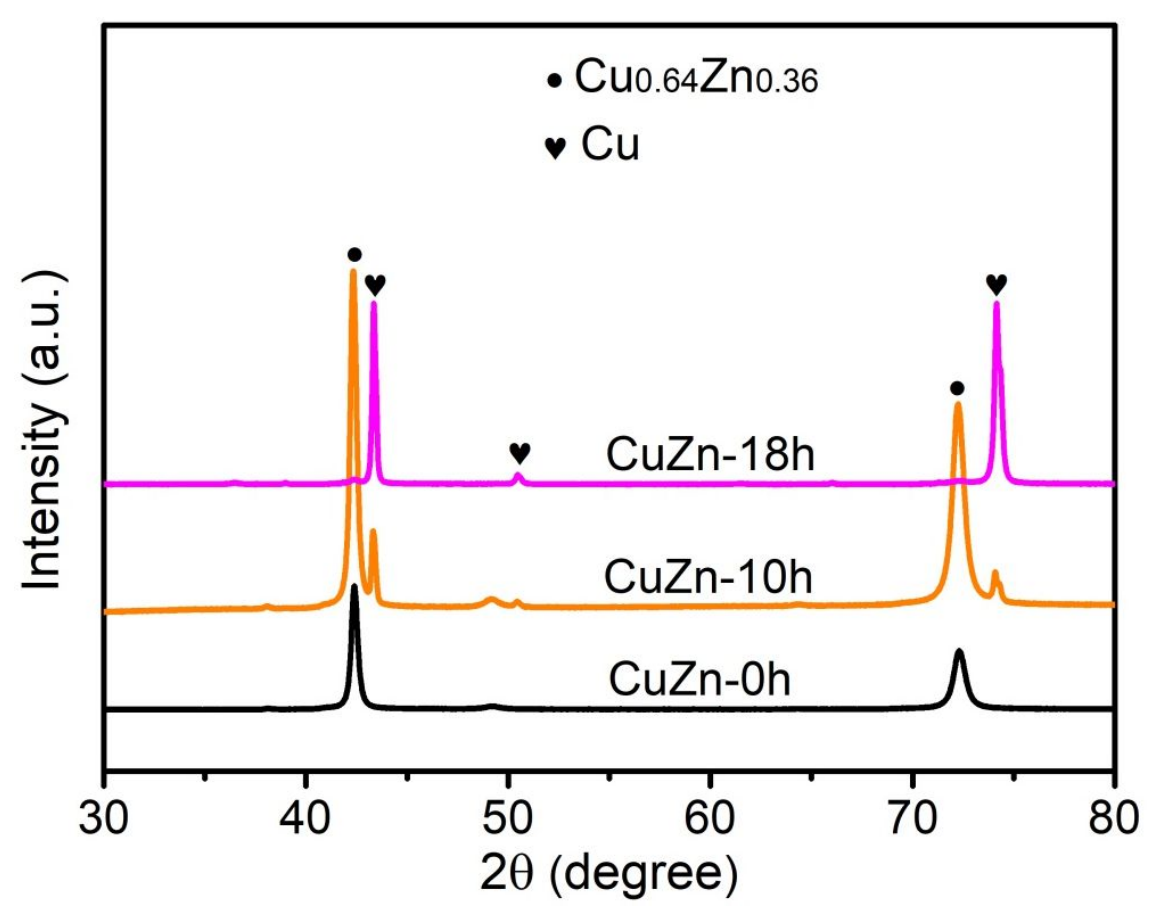

Figure S5. XRD patterns of the $\mathrm{Cu}-\mathrm{Zn}$ alloy with different dealloying time.

The XRD patterns of the CuZn alloy with different dealloying times are presented in Figure S5. When the dealloying time is increased from $0 \mathrm{~h}$ to $18 \mathrm{~h}$, the $\mathrm{Cu}_{0.64} \mathrm{Zn}_{0.36}$ phase gradually becomes bare $\mathrm{Cu}$ phase, indicating the $\mathrm{Zn}$ sites in the $\mathrm{CuZn}$ alloy have been reduced to zero. Meanwhile, as shown in Figure S6, the 3D porous $\mathrm{CuZn}$ alloy with a dealloying time of $18 \mathrm{~h}$ also has much large pores than that of the $3 \mathrm{D}$ porous $\mathrm{CuZn}$ with a dealloying time of $10 \mathrm{~h}$ or 14h (Figure 1c,f). However, when all the Zn sites in the CuZn alloy are deallocated, the 3D porous $\mathrm{CuZn}$ alloy with a dealloying time of $18 \mathrm{~h}$ is fragile and it is not benefit for the fabrication of $\mathrm{Li} / \mathrm{CnZn}$ composite in the thermal infusion process. For the 3D porous $\mathrm{CuZn}$ $10 \mathrm{~h}$, it has much less pores than the $3 \mathrm{D}$ porous $\mathrm{CuZn}-14 \mathrm{~h}$ alloy and thus cannot to pre-store more Li than the CuZn-14h alloy. Therefore, we selected the CuZn alloy with a dealloying time of $14 \mathrm{~h}$ as the substrate material in our experiment. 


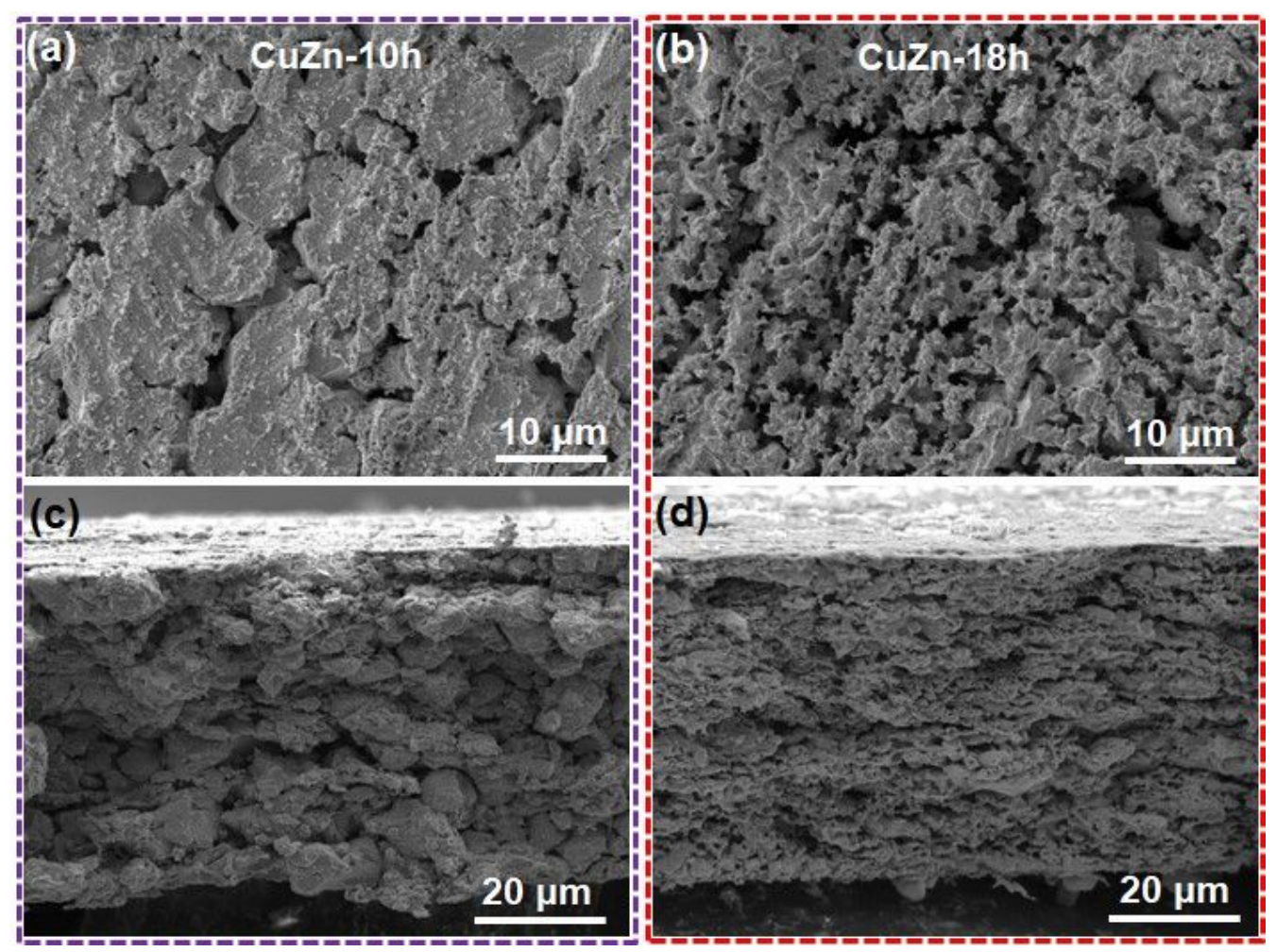

Figure S6. The surface and cross sectional SEM images of the CuZn alloy with different dealloying time of $10 \mathrm{~h}(\mathrm{a}, \mathrm{c})$ and $18 \mathrm{~h}(\mathrm{~b}, \mathrm{~d})$. 


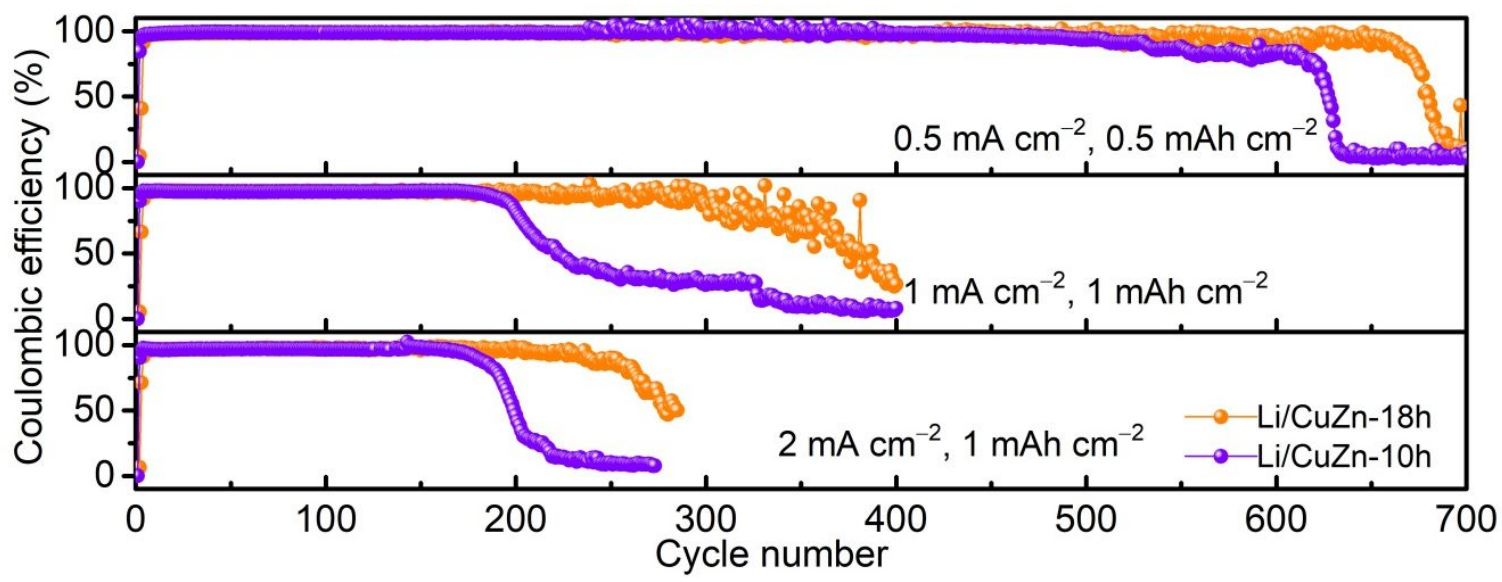

Figure S7. The Coulombic efficiency of the $3 \mathrm{D}$ porous $\mathrm{CuZn}-10 \mathrm{~h}$ and $\mathrm{CuZn}-18 \mathrm{~h}$ at various current densities of $0.5,1.0$, and $2.0 \mathrm{~mA} \mathrm{~cm}^{-2}$. 

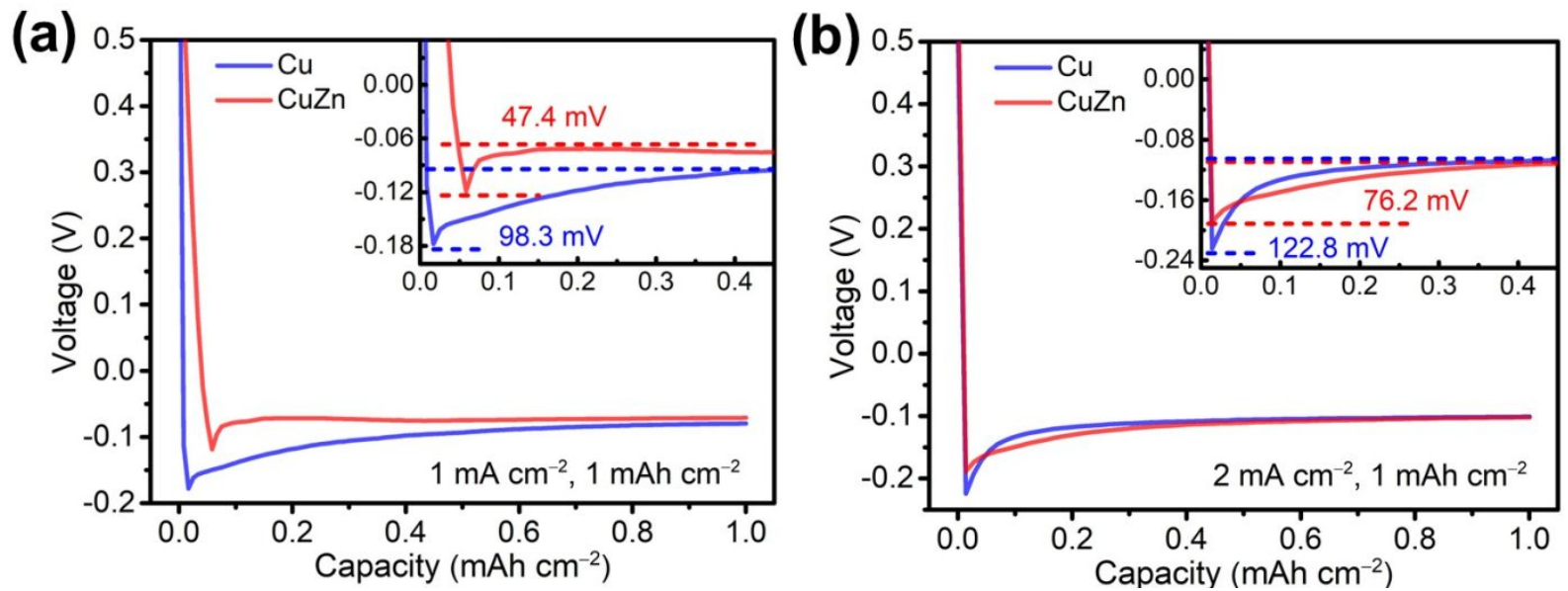

Figure S8. The voltage-capacity curves of $\mathrm{Cu}$ and $\mathrm{CuZn}-14 \mathrm{~h}$ electrode during Li nucleation at a) $1 \mathrm{~mA} \mathrm{~cm}-2$ and b) $2 \mathrm{~mA} \mathrm{~cm}^{-2}$. 


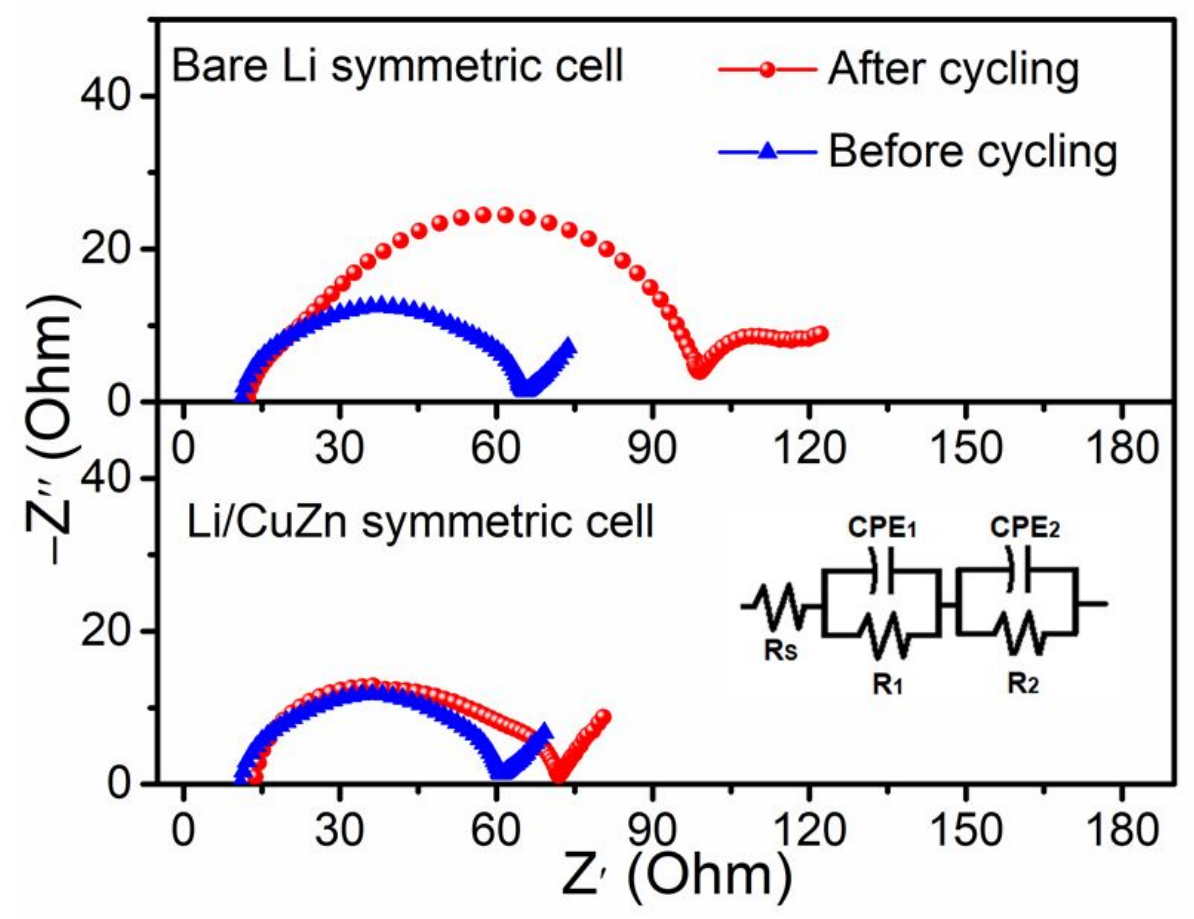

Figure S9. The EIS spectra of the bare Li foil and 3D Li/CuZn composite assembled symmetric cells before and after cycling in Figure 2d. Inset is the equivalent circuit of the EIS spectra and the corresponding simulation results are shown in Table S3. 


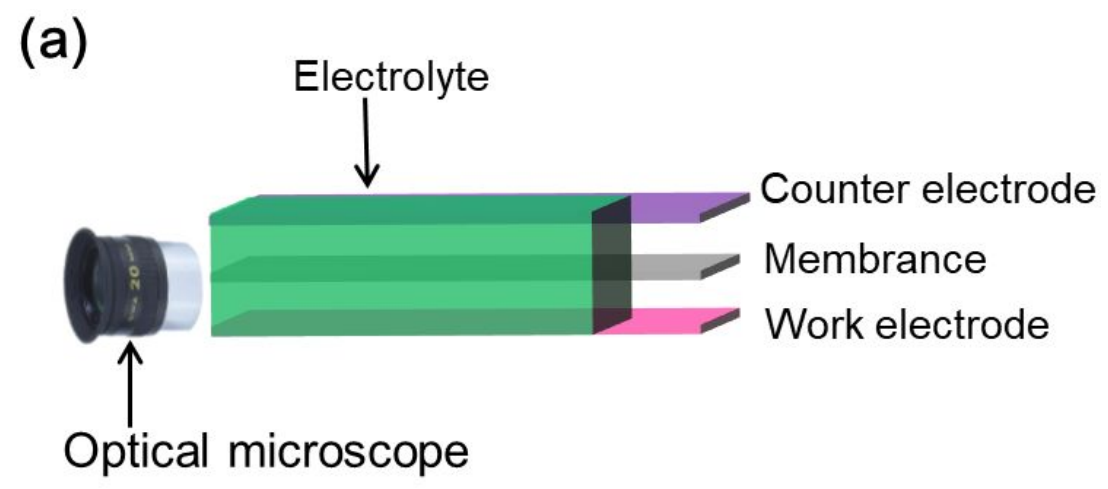

(b)

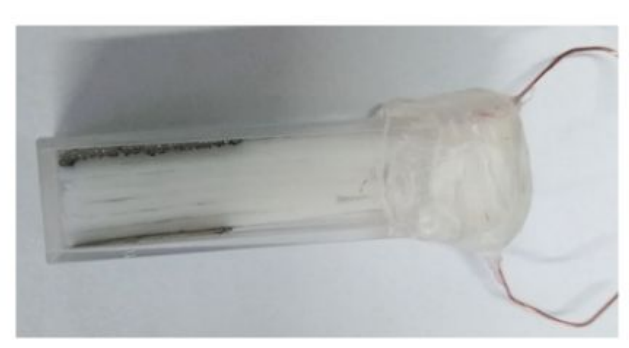

Figure S10. (a) Schematic illustration of the operando optical microscope. (b) The digital image of actual battery device for operando optical investigation. 


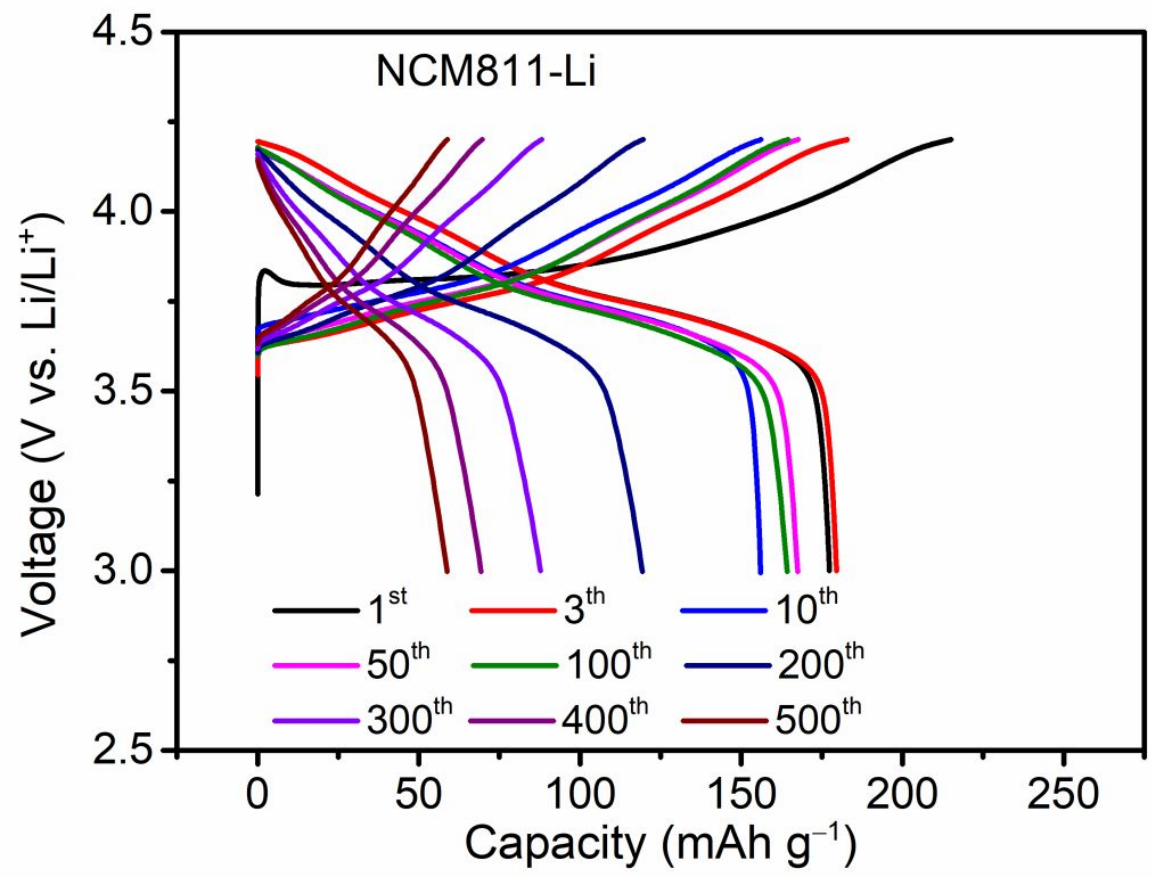

Figure S11. Galvanostatic charge/discharge curves of the NCM811-Li battery at the $1^{\text {st }}, 3^{\text {th }}$, $10^{\text {th }}, 50^{\text {th }}, 100^{\text {th }}, 200^{\text {th }}, 300^{\text {th }}, 400^{\text {th }}$, and $500^{\text {th }}$ cycles. 


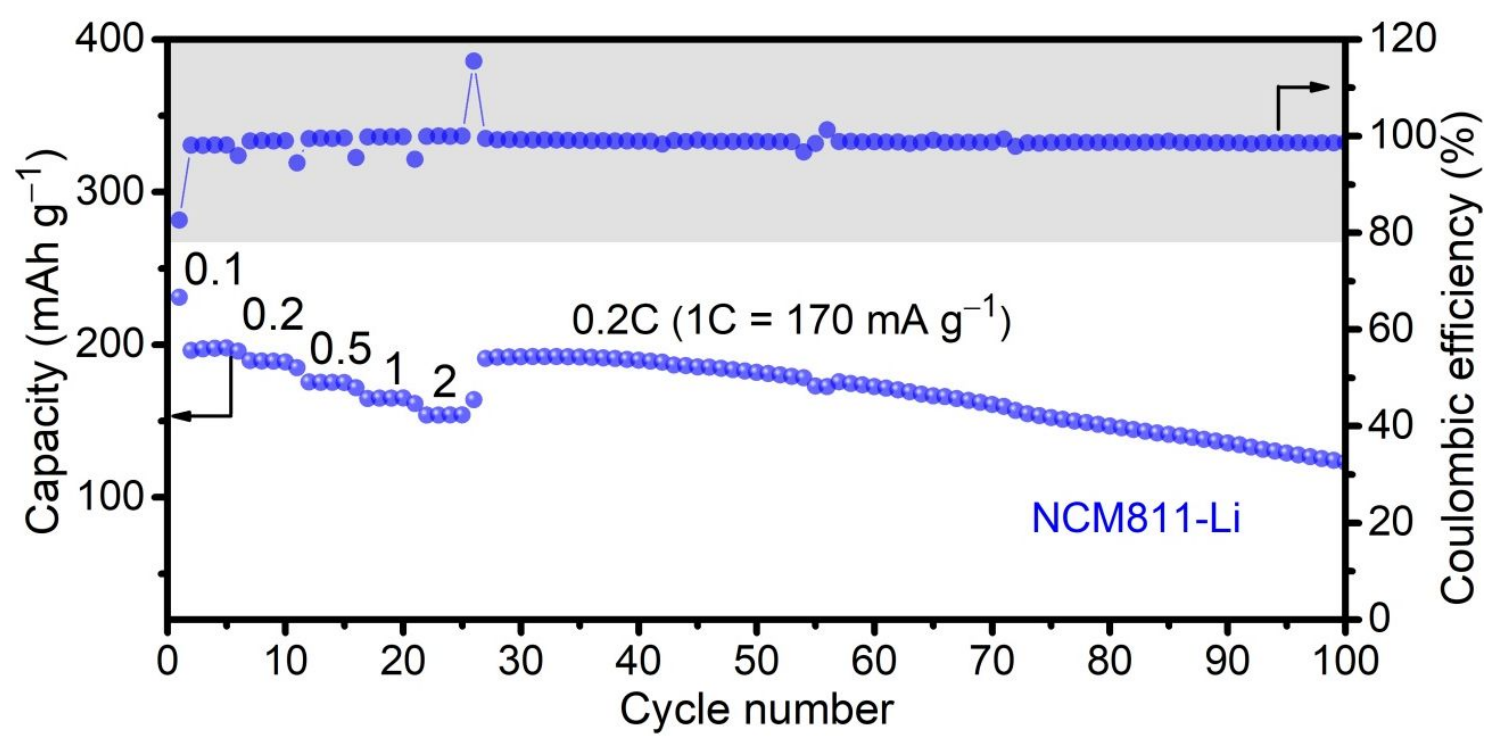

Figure S12. Rate capability of the NCM811-Li at various rates of $0.1,0.2,0.5,1,2,0.2 \mathrm{C}(1 \mathrm{C}$ $\left.=170 \mathrm{~mA} \mathrm{~g}^{-1}\right)$. 

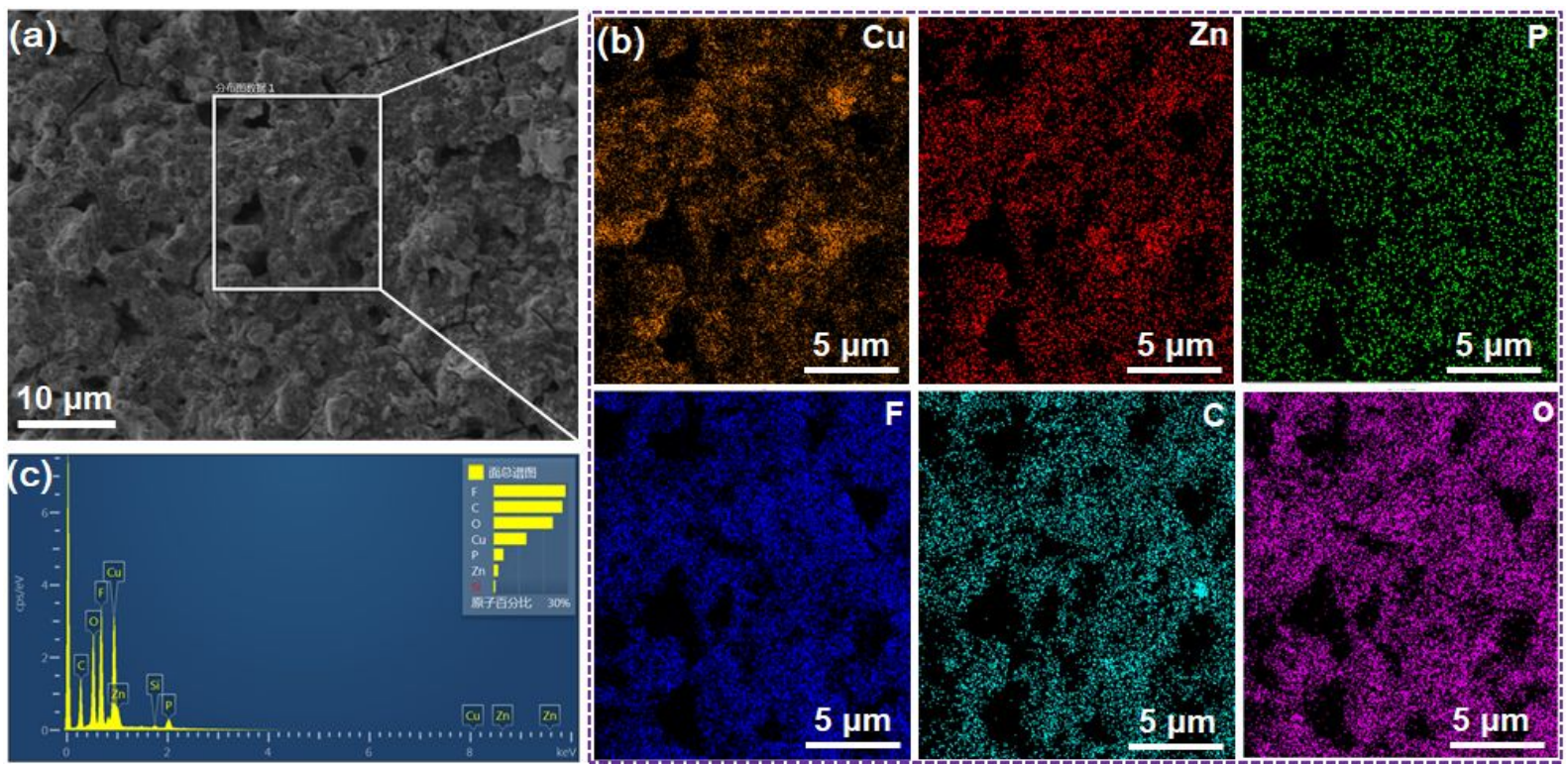

Figure S13. (a) SEM image of Li/CuZn-14h composite after 500 cycles, and corresponding elemental mapping images of (b) $\mathrm{Cu}, \mathrm{Zn}, \mathrm{P}, \mathrm{F}, \mathrm{C}$, and $\mathrm{O}$ as well as its (c) EDS pattern. 


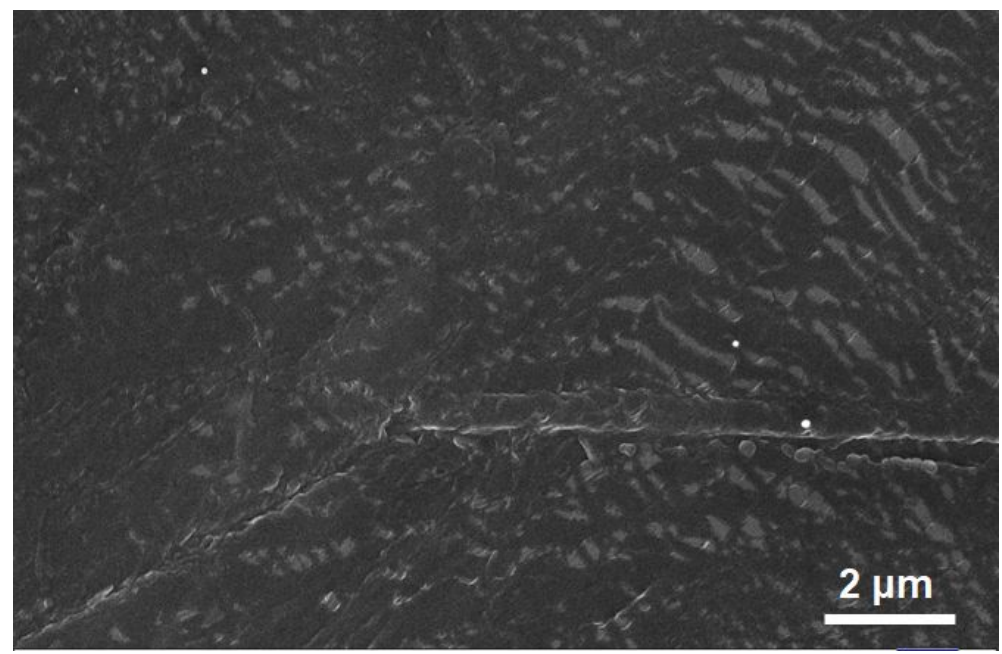

Figure S14. Surface SEM image of the bare Li foil before cycling. 


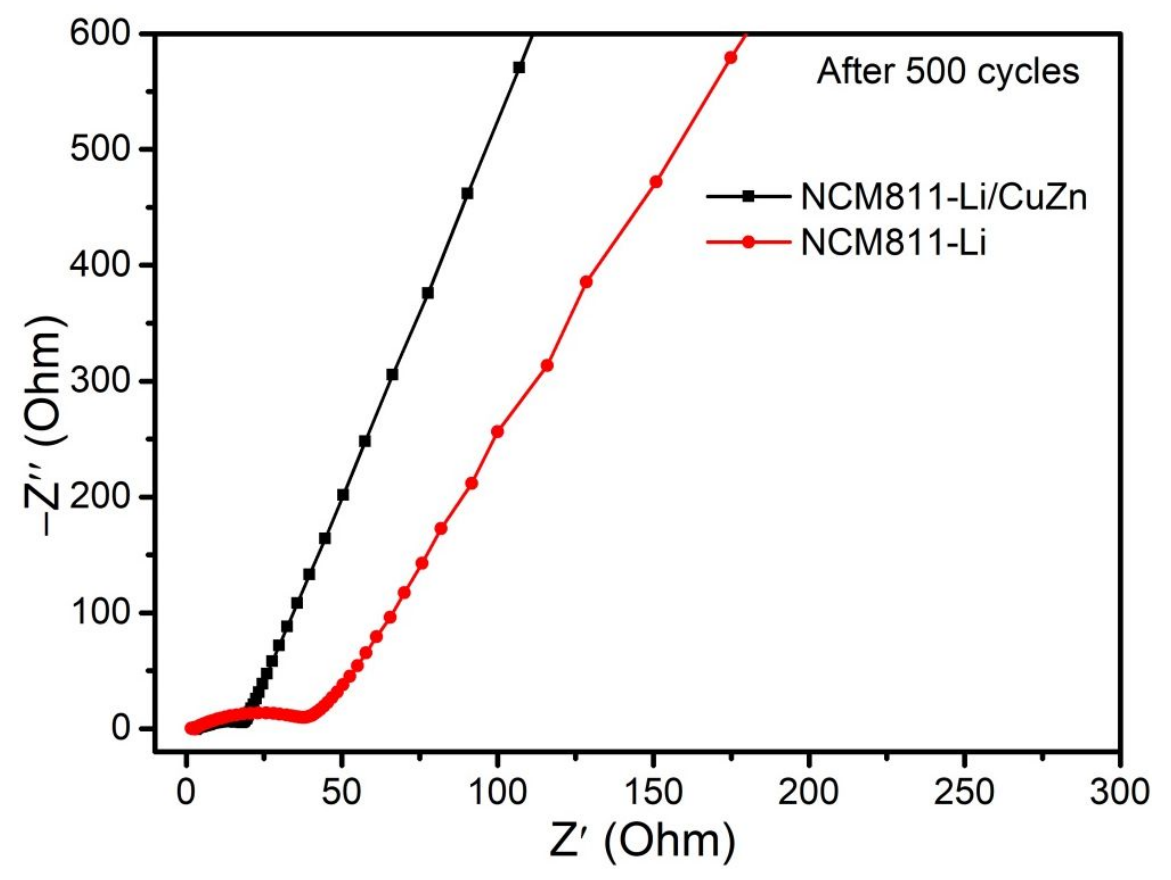

Figure S15. Nyquist plots of the full cells as marked after 500 cycles. 


\section{REFERENCES}

(1) Yun, Q.; He, Y.-B.; Lv, W.; Zhao, Y.; Li, B.; Kang, F.; Yang, Q.-H., Chemical Dealloying Derived 3D Porous Current Collector for Li Metal Anodes. Adv. Mater. 2016, 28, 6932-6939.

(2) Yang, Q. ; Liang, S. ; Han, B. ; Wang, J.; Mao, R. Preparation and Properties of Enhanced Bulk Nanoporous Coppers. Mater. Lett. 2012, 73, 136-138. 